\title{
BMJ Open Methamphetamine use in Central Germany: protocol for a qualitative study exploring requirements and challenges in healthcare from the professionals' perspective
}

\author{
Laura Hoffmann, ${ }^{1}$ Nadine Schumann, ${ }^{1}$ Thomas Fankhaenel, ${ }^{2}$ Carolin Thiel, ${ }^{2}$ \\ Andreas Klement, ${ }^{2}$ Matthias Richter ${ }^{1}$
}

To cite: Hoffmann L, Schumann N, Fankhaenel T, et al. Methamphetamine use in Central Germany: protocol for a qualitative study exploring requirements and challenges in healthcare from the professionals' perspective. BMJ Open 2016;6:e011445. doi:10.1136/bmjopen-2016011445

- Prepublication history for this paper is available online To view these files please visit the journal online (http://dx.doi.org/10.1136/ bmjopen-2016-011445)

Received 8 February 2016 Revised 24 March 2016 Accepted 13 April 2016

\section{(a) CrossMark}

${ }^{1}$ Institute of Medical Sociology, Martin Luther University Halle-Wittenberg, Halle, Germany

${ }^{2}$ Section of General Medicine, Martin Luther University Halle-Wittenberg, Halle, Germany

Correspondence to Laura Hoffmann; laura.hoffmann@medizin. uni-halle.de

\section{ABSTRACT}

Introduction: The synthetic drug methamphetamine with its high addiction potential is associated with substantial adverse health effects. In Germany, especially Central Germany, the increase in the consumption of methamphetamine has exceeded that of other illegal drugs. The treatment system and service providers are facing new challenges due to this rise in consumption. This qualitative study will explore the demand created by the increasing healthcare needs of methamphetamine-addicted persons in Central Germany, and the difficulty of rehabilitating addicted people.

Methods and analysis: The collection of empirical data will take place in a consecutive, two-stage process. In the first part of data collection, the experiences and perspectives of 40 professionals from numerous healthcare sectors for methamphetamineaddicted persons will be explored with the help of semistructured face-to-face interviews and probed by the research team. These findings will be discussed in 2 focus groups consisting of the participants of the face-to-face interviews; these group discussions comprise the second part of the data collection process. The interviews will be audio recorded, transcribed, and then subjected to qualitative content analysis.

Ethics and dissemination: All interviewees will receive comprehensive written information about the study, and sign a declaration of consent prior to the interview. The study will comply rigorously with data protection legislation. The research team has obtained the approval of the Ethical Review Committee at the Martin Luther University Halle-Wittenberg, Germany. The results of the study will be published in highquality, peer-reviewed international journals, presented at several congresses and used to design follow-up research projects.

\section{Trial registration number:} VfD_METH_MD_15_003600.

\section{Strengths and limitations of this study}

- This qualitative study will provide new insights on increasing healthcare needs of methamphetamine-addicted persons, and the challenges related to rehabilitative measures from an experts' perspective.

- It explores structural deficits and challenges in the treatment, as well as strategies and solutions to deduce potential for optimal treatment for methamphetamine addiction.

- It will help to enable more timely integration of the increasing number of methamphetamine users into the rehabilitative treatment system and provide for adequate treatment to them in the future.

- Given the diversity of national healthcare systems, these findings cannot entirely be transferred to other healthcare systems.

\section{INTRODUCTION}

Methamphetamine: epidemiology and health consequences

The use of methamphetamine (crystal methamphetamine, crystal meth), one of the most widespread psychostimulants worldwide, has reached epidemic proportions in the past decade. ${ }^{1-4}$ Crystal meth belongs to the class of amphetamine-type stimulants (ATS), which are consumed by around 24 million users worldwide. ${ }^{3}$ It is estimated that in 2014 about 1.3 million young adults (aged 1534 years) in Europe consumed amphetamines. ${ }^{2}$ In fact, in 2011, methamphetamine accounted for nearly $71 \%$ of all ATS seizures worldwide. ${ }^{3}$ Several studies have shown that methamphetamine ranks highest among the illicit drugs consumed in many countries 
after cannabis. ${ }^{1}{ }^{2}{ }^{5-9}$ It is enormously popular and has created subcultures of methamphetamine users all over the globe, and is thus associated with a high addictive potential. $^{3-5} 1011$ In Germany, the increase in the consumption of (meth-)amphetamine has outpaced that of all other drugs (2013: 19.210 first-time hard drug user; of these, 13.721 first-time (meth-)amphetamine user). ${ }^{5}$ The current German Statistical Report on substance abuse treatment reveals an increase in outpatient and inpatient addiction treatment and counselling due to the use of 'stimulants'. ${ }^{12}$

Methamphetamine, with its high addiction potential, is associated with substantial adverse health effects that include dermatological or cardiovascular diseases, cognitive impairments, and mental health problems such as depressions or psychosis. ${ }^{4} 10 \quad 11 \quad 13-20$ Often polyvalent consumption with other substances such as alcohol, cannabis and hallucinogenic exacerbates these adverse health effects. ${ }^{12}{ }^{21}{ }^{22}$ Furthermore, there is strong evidence that methamphetamine harms its users' social relationships, and often leads to legal and economic problems. 19212324

Given its proximity to the Czech Republic, Central Germany has been hit by the rise of methamphetamine consumption. $^{2}$ The Czech Republic is the main production region for the methamphetamine sold in Central Germany. In 2013, the federal state of Saxony witnessed an increase in the number of clients in the sector of 'illicit drugs', which is primarily due to the increase in the number of methamphetamine users. ${ }^{25}$ This general trend has been observed for 5 years and has continued in 2014. ${ }^{26}$ In Saxony, most of the illicit substances consumed belonged to the class of stimulants (of which $>97 \%$ is crystal meth). ${ }^{26}$ About two-thirds of the clients who use illicit drugs show symptoms of addiction to crystal meth. ${ }^{26}$

\section{Consumer groups, motives and consumption pattern}

The users of methamphetamine and their motivations for its use have been well documented in international research. ${ }^{19} 21 \quad 27-29$ Methamphetamine consumption is not limited to a special target group (eg, the party scene), but can be found in different social groups. It is often used to raise one's mental ability to work longer, to do more housework, and to care for children (especially by young mothers). ${ }^{19} 21$ It is also used for selfmedication (eg, as an antidepressant or painkiller) to foster feelings of 'being in control' and 'fully focused', to 'have more fun' and also to 'escape from current life' or to lose weight. ${ }^{19} 21$ A first explorative study on 400 (meth-)amphetamine users in Germany also identified different consumer groups and motives for methamphetamine use. ${ }^{30}$ Some people use it in the school context or at work, but there are also users with mental illness and consumers with children. ${ }^{30}$ Beside its function as a 'party drug', the results of the study showed that in Germany methamphetamine is also often used to raise mental ability in different contexts. Half of the interviewees reported increased demands at work as a reason for their crystal consumption. ${ }^{30}$

\section{Methamphetamine treatment and treatment approaches}

So far, behavioural therapies, such as cognitive-behavioural therapy or contingency management, have proven to be the most effective treatments for methamphetamine addiction. ${ }^{4} 9$ 31-35 Although medications have shown to be effective in treating some substance-use disorders (eg, opioid addiction) and there is compelling evidence for the effectiveness of certain medications, there are currently no medications to counter the effects of meth amphetamine or reduce its abuse by an individual addicted to the drug. ${ }^{49}{ }^{35}$ For this reason, treatment of methamphetamine addiction is a serious challenge that has yet to be met.

In Germany, there is widespread availability of counselling and treatment for drug-addicted persons; this is subdivided into measures of early diagnosis and intervention (identification of risky consumption), and measures of acute and post-acute care (withdrawal therapy and long-term rehabilitation therapy) as well as measures of aftercare. ${ }^{36}$ Based on an interdisciplinary and integrated treatment service, the focus lies on medical rehabilitation with the aim of the employability and capacity of the affected people in different occupations and in everyday life. ${ }^{37} 38$ Generally, measures of rehabilitation are financed by German pension insurance or German health insurance, depending on the insurance conditions of the insured person. Access to the addiction treatment system is determined by different caregivers such as counselling centres, family doctors and psychotherapists, and by acute care hospitals. ${ }^{12}$ An effective and efficient treatment of the drug addicts requires the intensive cooperation of the different care sectors and actors. Nevertheless, experiences from different care contexts have shown that cooperation is often complicated by different kinds of expertise, treatment concepts, and financing structures. ${ }^{39-41}$

\section{REQUIRED RESEARCH}

The majority of existing qualitative research has focused on users' perspectives, for example, their consumption patterns and their motivation, their need for adequate healthcare, and their experience with the drug addiction treatment system. ${ }^{29} 42-46$ These studies examine the history of abuse, requirements of addiction therapy, experiences and wishes from the viewpoint of the methamphetamine users themselves. Owing to the diversity of national healthcare systems, these findings cannot entirely be transferred to the German healthcare system; therefore, the question about the status of medical care for methamphetamine users in Germany remains unanswered.

So far, there have been no studies assessing the current treatment structures for methamphetamine users in Central Germany. It is, therefore, necessary to 
first explore basic knowledge from the expert's perspective. The use of expert interviews is highly recommended given the dearth of research on this topic in Germany. For example, it is unknown how people addicted to methamphetamine gain access to treatment services, in what ways they differ from each other, and how the caregivers-especially rehabilitation centreswill be able to accommodate the growing healthcare requirements of these affected groups in the future. Furthermore, it is important to discover how the rising number of methamphetamine users can be integrated in a timely manner into the counselling and treatment system, and to determine what are the barriers to the integration.

\section{METHODS AND ANALYSIS}

\section{Aims, objectives and research questions}

This qualitative study will explore the demands on increasing healthcare needs of methamphetamineaddicted persons in Central Germany, and structural challenges (eg, collaboration of sponsors and interface management) related to rehabilitative measures as well as explore strategies and solutions to deduce potential for an optimal treatment of methamphetamine addiction. Therefore, the study will focus on the perspectives of professionals in the outpatient counselling centres, and in inpatient facilities such as the acute care and rehabilitation clinics. The professionals will be questioned about central aspects and challenges of treating the affected persons; they will be asked about their own experiences with these addicted persons and their assessments of these risk groups. The content of, access to, utilisation of and the quality of rehabilitative treatment for methamphetamine users will be explored as will the potential for optimisation within these subgroups from the experts' perspective.

The following research questions will be the focus of our study:

- How is the current treatment structure for methamphetamine-addicted persons constructed? Where are the central challenges (access to, use of and quality of treatment) from the experts' perspective?

- With which groups of methamphetamine users are the experts of the different counselling and treatment institutions confronted (consumption pattern, consumption motivation, sociodemographic aspects, seriousness of addiction, etc)? How are these groups different? How must rehabilitative treatment institutions adjust to the growing healthcare needs of these different addicted persons?

- Which potential for optimisation of an adequate treatment for methamphetamine users can be deduced from the experiences and assessments of the experts for the financiers of rehabilitative measures, with the aim to bring in a successful (re)integration with school, education and occupation?

\section{Study design}

An inductive qualitative approach that aims at exploration, instead of a deductive approach, will be used to answer these research questions. ${ }^{47}{ }^{48}$ Qualitative methods have become a key method in health services research because these allow for subject orientation and consideration of different perspectives for treatment problems. ${ }^{4-51}$ For this research project, the inductive approach offers the chance to reconstruct the experiences related to practice and views of professionals in the treatment of addiction. It also explores perceived deficits in the treatment from the practitioners' perspective so as to deduce potential for optimal treatment of methamphetamine addiction. The use of expert interviews is highly recommended given the dearth of research on this topic. At this stage, particularly, where the topic has not been well documented and structured, such interviews provide more compact data production than other methods of data collection, such as a participant's observation or a quantitative study, which are much more time-consuming and expensive. ${ }^{52}$ Hence, the empirical data collection will take place in a consecutive, two-stage process with separate semistructured face-to-face interviews with experts followed by focus groups of experts across professions. Focus groups are a resource-efficient form of group discussions and allow the capture of collective knowledge concerning a special topic while opening up new subject areas. ${ }^{53} 54$ Therefore, to explore the current treatment structures of methamphetamine-addicted persons and their potential deficits, the combination of semistructured interviews and focus groups is suitable.

\section{Identification of participants and sample size}

Approximately 40 professionals across the treatment system of methamphetamine-addicted persons will be interviewed in order to acquire a broad range of expert knowledge and experience. The experts include family doctors and staff members of counselling centres, acute care facilities and rehabilitation treatment centres (table 1).

Table 1 Sample face-to-face interviews $(\mathrm{N}=40)$ and focus groups $(\mathrm{N}=2)$

\begin{tabular}{lc}
\hline Sector of care & Interv \\
\hline 1. Face-to-face interviews & \\
Family doctors & 10 \\
Counselling centres & 10 \\
Acute care & 10 \\
Rehabilitation & 10 \\
Total & $40^{*}$ \\
2. Focus groups & \\
8-10 professionals from all 4 sectors of & 2 \\
care &
\end{tabular}

*If a content saturation appears in the stakeholder interviews before reaching the planned interview number $(\mathrm{N}=10$ interviews per sector of care), this number can decrease. 
Family doctors, the first professional contact for health questions, are in the best position to guide methamphetamine users to treatment in a timely manner. They are trustworthy and reliable counsellors, and in the case of a solid physician-patient relationship, they offer a context for discussion of issues such as addiction.

Outpatient counselling centres ready methamphetamine-addicted patients for inpatient treatment. Counselling centres support patients through consultation and therapeutic talks up to the beginning of the therapy; afterwards they are responsible for aftercare treatment.

Institutions with obligatory psychiatric care and under specialised medical management implement inpatient or outpatient acute care for methamphetamine-addicted patients. The purpose of acute treatment is, beside the transfer in self-help, the preparation of measures for follow-up treatment by institutions of the professional addiction treatment system by taking into account the psychic, somatic, and social dimensions of this illness.

The rehabilitation of methamphetamine-addicted persons aims at the recovery and preservation of active participation in normal life, including education, occupation, family, and society as well as the development of compensation strategies in case of remaining health disorders.

Findings of the face-to-face interviews will be discussed in focus groups in the second stage of the project with the aim to develop concrete suggestions for structural improvements (eg, to optimise cross-sectoral cooperation) for optimal treatment of methamphetamine addiction. This offers the opportunity to reveal problems at the interface of healthcare sectors and to develop optimisation measures. Two focus groups should take place with the greatest possible heterogeneity of professionals. This is an established practice ${ }^{50}$ to bring in a broad range of opinions and views to the subject area.

\section{Recruitment and data collection}

The recruitment of all study participants is organised in cooperation with the section of general medicine at the university clinic, Halle-Wittenberg. The federal Centers for Addiction Issues (Landesstellen für Sucht) of Saxony, Saxony-Anhalt and Thuringia will also support the recruitment. The extent and form of recruitment are adapted to the responsiveness of the target group. It will occur in a consecutive procedure by telephone or by letter. All face-to-face interviews will be conducted by the same researcher in a private, undisturbed room at the participant's place of employment (eg, clinic or medical office).

For the two planned focus groups, the participants from the face-to-face interviews will be asked for renewed participation. Given the difficulty faced in the recruitment of family doctors, incentives of the amount of $€ 50$ will be paid for interview participation. For both the face-to-face interviews and for the focus groups, a semistructured interview guide will be developed, which will contain open questions and set topics of conversation that will be raised (in no particular sequence) during the interview.

The following key topics will be explored during the semistructured, guided interviews:

- Experiences with methamphetamine-addicted persons (consumption groups, motives, patterns, social demographics, social economy, general living conditions, state of health, comorbidity, etc).

- Assessment of the current treatment structure for methamphetamine-addicted persons with regard to access, utilisation and quality.

- Specifics in the treatment of methamphetamine addiction in comparison to other addictive disorders (eg, longer duration of treatment, abstinence motivation, relapse, etc).

- Key difficulties in the current treatment for methamphetamine-addicted persons (among other things information/knowledge, cooperation/interface management).

- Improvement suggestions/wishes (especially in the area of rehabilitation).

Before any data are collected, the interview guide will be pilot tested with a minimum of two professionals.

\section{Data analysis}

All interviews will be audio recorded, transcribed, and imported into MAXQDA software, which will be used to assist the data management and analyses. The expert interviews and the focus groups will be subjected to qualitative content analysis. ${ }^{55-58}$ During the first step of 'open coding', short, concise and relatively abstract concepts (codes) that characterise the segment will be developed. In the second step, 'axial coding' will look at a particular category more closely, and relationships between this category and other categories will be assessed. As a third step, 'selective coding' will focus on key categories and prepare theoretical generalisations. At the same time, relationships and interactions between topics will be examined. ${ }^{55}$ The research associate (LH) will conduct the coding and there will be a continuous exchange among the associate, the head of the project (MR and $\mathrm{AK}$ ) and another research associate (NS), as well as a presentation of categories and interpretations in the qualitative research group at the Institute of Medical Sociology (IMS). Finally, the consolidated criteria for reporting qualitative research (COREQ) will be taken into account to ensure high-quality qualitative research. ${ }^{59}$

\section{ETHICS AND DISSEMINATION}

The IMS has obtained approval for the study from the Ethical Review Committee of the Medical Faculty at Martin Luther University, Halle-Wittenberg, and its recommendations for the study have been implemented. The Committee did not express any ethical concerns about the study. The study complies rigorously with data protection legislation, and will be conducted according 
to the principles of the Helsinki Declaration, following standard of good scientific practice. All participants will receive an information sheet, which will describe the study. They will also sign a consent form before conducting the interview. Participation is voluntary and may be discontinued at any point. There will be no consequences for anyone who decides not to participate. Consent withdrawal is possible at any time, in which case all relevant data will be deleted. To ensure data protection, each participant will receive an individual identification number for the purposes of pseudonymisation. All data will be collected under this pseudonym. As a result, no individuals or places will risk identification and all personal data will be protected. The name of the interviewee will not be mentioned during the interview to prevent ascription of the interviews and transcripts to any individual. The gathered interview data (record and transcript), personal data (declaration of consent), and the list assigning pseudonym to individuals will be stored separately in locked locations. The declaration of consent and the pseudonym assignment list will be accessible only to members of the research team. The pseudonym assignment list will be deleted once data collection has been completed. The results of the study will be published in high-quality peer-reviewed international journals, and will be presented at several congresses and research conferences. These will also be used as the basis of a follow-up study, which might contain interviews with methamphetamine users to explore their special needs regarding rehabilitation therapy in Central Germany. A summary of the results will also be sent to participants who have indicated a wish to receive them.

\section{RELEVANCE TO PRACTICE/CONCLUSION}

The results of this qualitative study will provide an interdisciplinary overview on the healthcare requirements of methamphetamine-addicted persons in Central Germany in addition to what experts view as the challenges to successful treatment. Current treatment structures for affected persons will be collected as well as perceived optimisation possibilities from the experts' point of view will be explored. This enables timely integration of the increasing number of methamphetamine users into the rehabilitative treatment system, and provision of adequate treatment for them in the future. Given the diversity of the national healthcare systems, these findings cannot entirely be transferred to other healthcare systems.

Contributors LH wrote the initial draft of this manuscript, will conduct the interviews and focus groups, and analyse the data. CT is responsible for the recruitment of the study participants. MR is the principal investigator of the study and is responsible for the conception of the project, led the grant application and critically reviewed the manuscript. MR and NS wrote the original study protocol in collaboration with TF and AK. All the authors have read and approved the final version of the manuscript.

Funding This work is supported by the German Pension Insurance for Central Germany (Deutsche Rentenversicherung Mitteldeutschland).
Competing interests None declared.

Ethics approval Ethical Review Committee of the Medical Faculty of Martin Luther University, Halle-Wittenberg (reference number 2015-35).

Provenance and peer review Not commissioned; externally peer reviewed.

Open Access This is an Open Access article distributed in accordance with the Creative Commons Attribution Non Commercial (CC BY-NC 4.0) license, which permits others to distribute, remix, adapt, build upon this work noncommercially, and license their derivative works on different terms, provided the original work is properly cited and the use is non-commercial. See: http:// creativecommons.org/licenses/by-nc/4.0/

\section{REFERENCES}

1. UNODC World Drug Report 2015. United Nations Office on Drugs and Crime (ed.) Vienna. https://www.unodc.org/documents/wdr2015/ World_Drug_Report_2015.pdf (accessed 25 May 2016).

2. EMCDDA European Drug Report 2015. Trends and Developments. European Monitoring Centre for Drugs and Drug Addiction (ed.) Lisbon. http://www.emcdda.europa.eu/attachements.cfm/att 239505_EN_TDAT15001ENN.pdf (accessed 25 May 2016).

3. Chomchai C, Chomchai S. Global patterns of methamphetamine use. Curr Opin Psychiatry 2015;28:269-74.

4. Courtney KE, Ray LA. Methamphetamine: an update on epidemiology, pharmacology, clinical phenomenology, and treatment literature. Drug Alcohol Depend 2014;143:11-21.

5. Die Drogenbeauftragte der Bundesregierung: Drogen- und Suchtbericht 2014. Bundesministerium für Gesundheit (Hrsg). Berlin. http://www.drogenbeauftragte.de/fileadmin/dateien-dba/ Presse/Downloads/Drogen-_und_Suchtbericht_2014_Gesamt_ WEB_07.pdf (accessed 25 May 2016).

6. Maxwell JC, Rutkowski BA. The prevalence of methamphetamine and amphetamine abuse in North America: a review of the indicators, 1992-2007. Drug Alcohol Rev 2008;27:229-35.

7. McKetin R, Kozel N, Douglas J. et al The rise of methamphetamine in Southeast and East Asia. Drug Alcohol Rev 2008;27:220-8.

8. Degenhardt L, Roxburgh A, Black E, et al. The epidemiology of methamphetamine use and harm in Australia. Drug Alcohol Rev 2008;27:243-52.

9. Rawson RA. Current research on the epidemiology, medical and psychiatric effects, and treatment of methamphetamine use. $J$ Food Drug Anal 2013;21:S77-81.

10. Buxton JA, Dove NA. The burden and management of crystal meth use. CMAJ 2008;178:1537-9.

11. EMCDDA Problem amphetamine and methamphetamine use in Europe. European Monitoring Centre for Drugs and Drug Addiction (ed.) Luxembourg. 2010. http://www.emcdda.europa.eu/system/files/ publications/578/EMCDDA_SI10_Amphetamines_242746.pdf (accessed 25 May 2016)

12. Brand $H$, Steppan $M$, Künzel J, et al. Suchthilfe in Deutschland 2013. Jahresbericht der Deutschen Suchthilfestatistik (DSHS). Hg. v. IFT Institut für Therapieforschung. 2014. http://www. suchthilfestatistik.de/cms/images/dshs_jahresbericht_2013.pdf (accessed 25 May 2016)

13. Darke S, Kaye S, McKetin R, et al. Major physical and psychological harms of methamphetamine use. Drug Alcohol Rev 2008;27:253-62.

14. Petit A, Karila L, Chalmin F. Methamphetamine addiction: a review of the literature. J Addict Res Ther 2012(S1):006.

15. Thomasius R, Gouzoulis-Mayfrank E. Psychische und verhaltensbezogene Störungen durch Kokain, Amphetamine, Ecstasy und Halluzinogene. In: Schmidt LG, Gastpar M, Falkai P, et al. Hrsg. Evidenzbasierte Suchtmedizin. Behandlungsleitlinie Substanzbezogene Störungen. Köln: Deutscher Ärzte-Verlag, 2006:241-170.

16. McKetin R, Lubman DI, Baker AL, et al. Dose-related psychotic symptoms in chronic methamphetamine users. JAMA Psychiatry 2013;70:319-24.

17. Grant KM, LeVan TD, Wells SM, et al. Methamphetamineassociated psychosis. J Neuroimmune Pharmacol 2012;7: 113-39.

18. Vaerrier D, Greenberg MI, Miller SN, et al. Methamphetamine: history, pathophysiology, adverse health effects, current trends, and hazards associated with the clandestine manufacture of methamphetamine. Dis Mon 2012;58:38-89.

19. Maxwell JC. A new survey of methamphetamine users in treatment: who they are, why they like "meth," and why they need additional services. Subst Use Misuse 2014;49:639-44. 
20. Cruickshank CC, Dyer KR. A review of the clinical pharmacology of methamphetamine. Addiction 2009;104:1085-99.

21. Brecht ML, O'Brien A, von Mayrhauser C. et al Methamphetamine use behaviors and gender differences. Addict Behav 2004:29:89-106.

22. Brecht M-L, Greenwell L, Anglin MD. Substance use pathways to methamphetamine use among treated users. Addict Behav 2007;32:24-38

23. Sommers I, Baskin D, Baskin-Sommers A. Methamphetamine use among young adults: health and social consequences. Addict Behav 2006;31:1469-76.

24. Room R. Stigma, social inequality and alcohol and drug use. Drug Alcohol Rev 2005;24:143-55.

25. Sächsische Landesstelle gegen die Suchtgefahren e.V. Sucht 2013. Bericht der Suchtkrankenhilfe in Sachsen 2014. Dresden. http://www.lpr.sachsen.de/download/landespraeventionsrat/ Sucht2013.pdf (accessed 25 May 2016).

26. Sächsische Landesstelle gegen die Suchtgefahren e.V. Sucht 2014 Bericht der Suchtkrankenhilfe in Sachsen 2015. Dresden. http://www.slsev.de/fileadmin/user/Dokumente/Die_SLS/Sucht2014. pdf (accessed 25 May 2016)

27. Rhodes SD, Hergenrather KC, Yee LJ, et al. Characteristics of a sample of men who have sex with men, recruited from gay bars and internet chat rooms, who report methamphetamine use. AIDS Patient Care STDS 2007;21:575-83.

28. Degenhardt L, Coffey C, Carlin JB, et al. Who are the new amphetamine users? A 10-year prospective study of young Australians. Addiction 2007;102:1269-79.

29. Fast D, Kerr T, Wood E, et al. The multiple truths about crystal meth among young people entrenched in an urban drug scene: a longitudinal ethnographic investigation. Soc Sci Med 2014;110: 41-8.

30. Milin S, Lotzin A, Degkwitz $P$, et al. Amphetamin und Methamphetamin-Personengruppen mit missbräuchlichem Konsum und Ansatzpunkte für präventive Maßnahmen. Sachbericht. Hg. v. Zentrum für Interdisziplinäre Suchtforschung (ZIS). 2014. http://drogenbeauftragte.de/fileadmin/dateien-dba/Presse/ Downloads/ATS-Bericht_final.pdf (accessed 25 May 2016)

31. Lopez-Patton M, Kumar M, Jones D, et al. Childhood trauma and METH abuse among men who have sex with men: implications for intervention. J Psychiatr Res 2016;72:1-5.

32. Rawson RA, McCann MJ, Flammino F, et al. A comparison of contingency management and cognitive-behavioral approaches for stimulant-dependent individuals. Addiction 2006;101:267-74.

33. Roll JM. Contingency management: an evidence-based component of methamphetamine use disorder treatments. Addiction 2007;102 (Suppl 1):114-20.

34. Lee NK, Rawson RA. A systematic review of cognitive and behavioural therapies for methamphetamine dependence. Drug Alcohol Rev 2008:27:309-17.

35. Phillips KA, Epstein DH, Preston KL. Psychostimulant addiction treatment. Neuropharmacology 2014;87:150-60.

36. Schmidt LG, Gastpar M, Falkai P, et al. (Hrsg.) Evidenzbasierte Suchtmedizin. Behandlungsleitlinie Substanzbezogene Störungen. Deutscher Ärzte-Verlag 2006. Köln: 241-70.

37. Bundesverband für stationäre Suchtkrankenhilfe (2012) Therapie. Online verfügbar unter. http://www.suchthilfe.de/therapie/index.php zuletzt geprüft am 07.01.2016.

38. Deutsche Rentenversicherung Bund ( $\mathrm{Hg}$.) Entwöhnungsbehandlung -ein Weg aus der Sucht. 8. Auflage (6/2013), Nr. 305. Berlin. https://www.deutsche-rentenversicherung.de/cae/servlet/contentblob/ 232574/publicationFile/51584/entwoehnungsbehandlung.pdf (accessed 25 May 2016).

39. Deck R, Hg. Schnittstellen der medizinischen Rehabilitation. Lage: Jacobs (Rehabilitationsforschung), 2010.
40. Pohontsch N, Deck R. Optimierung der Zusammenarbeit von RehaKostenträgern, Reha-Einrichtungen und ambulanter Versorgung an den Schnittstellen der medizinischen Rehabilitation [abstract]. Gesundheitswesen 2012:74-A91.

41. Grundke S, Behrens J, Parthier K, et al. Rehabilitationszugangsund Schnittstellenoptimierung in der ambulanten Versorgung. Prävent Rehabil 2013;25:43-51.

42. Meade CS, Towe SL, Watt MH, et al. Addiction and treatment experiences among active methamphetamine users recruited from a township community in Cape Town, South Africa: a mixed-methods study. Drug Alcohol Depend 2015;152: 79-86.

43. Watt MH, Myers B, Towe SL, et al. The mental health experiences and needs of methamphetamine users in Cape Town: a mixed methods study. S Afr Med J 2015;105:685-8.

44. Boeri M, Gibson D, Boshears P. Conceptualizing social recovery: recovery routes of methamphetamine users. J Qual Crim Justice Criminol 2014;2:5-38.

45. Herbeck DM, Brecht ML, Christou D, et al. A qualitative study of methamphetamine users' perspectives on barriers and facilitators of drug abstinence. J Psychoactive Drugs 2014;46:215-25.

46. Gonzales R, Anglin MD, Glik DC, et al. Perceptions about recovery needs and drug-avoidance recovery behaviors among youth in substance abuse treatment. J Psychoactive Drugs 2013;45:297-303.

47. Schütze F. Eine sehr persönlich generalisierte Sicht auf qualitative Forschung. Zeitschrift für qualitative Bildungs-, Beratungs- und Sozialforschung 6 2005;2:211-48.

48. Taylor SJ, Bogdan R, DeVault M. Introduction to qualitative research methods: a guidebook and resource. John Wiley \& Sons, 2015.

49. Meyer T, Karbach U, Holmberg C, et al. [Qualitative research in health services research-discussion paper, Part 1: What is the idea?]. Gesundheitswesen 2012;74:510-15.

50. Karbach U, Stamer M, Holmberg C, et al, Arbeitsgruppe Qualitative Methoden des DNVF. [Qualitative research in health services research-discussion paper, Part 2: Qualitative research in health services research in Germany-an overview]. Gesundheitswesen 2012;74:516-25.

51. Curry LA, Nembhard IM, Bradley EH. Qualitative and mixed methods provide unique contributions to outcomes research. Circulation 2009;119:1442-52.

52. Bogner A, Littig B, Menz W. Das Experteninterview. Theorie, Methode, Anwendung. 2. Aufl. Wiesbaden: VS Verlag für Sozialwissenschaften, 2005.

53. Schulz M, Mack B, Renn O. Fokusgruppen in der empirischen Sozialwissenschaft. Von der Konzeption bis zur Auswertung. Wiesbaden: VS Verlag für Sozialwissenschaften (SpringerLink: Bücher), 2012

54. Rabiee F. Focus-group interview and data analysis. Proc Nutr Soc 2004:63:655-60.

55. Meuser M, Nagel U. Experteninterview und der Wandel der Wissensproduktion. In: Bogner A, Littig B, Menz W, Hrsg. Experteninterviews. Theorien, Methoden, Anwendungsfelder. 3. grundlegend überarbeitete Auflage. VS Verlag für Sozialwissenschaften, 2009.

56. Graneheim UH, Lundman B. Qualitative content analysis in nursing research: concepts, procedures and measures to achieve trustworthiness. Nurse Educ Today 2004;24:105-12.

57. Bos W, Tarnai C. Content analysis in empirical social research Int J Educ Res 1999;31:659-71.

58. Hsieh HF, Shannon SE. Three approaches to qualitative content analysis. Qual Health Res 2005; 15:1277-88.

59. Tong A, Sainsbury P, Craig J. Consolidated criteria for reporting qualitative research (COREQ): a 32-item checklist for interviews and focus groups. Int J Qual Health Care 2007;19:349-57. 